Удк 335.1

DOI: $10.14451 / 1.205 .238$

\title{
АКТУАЛЬНЫЕ ВОПРОСЫ ФОРМИРОВАНИЯ НЕФОРМАЛЬНОЙ ЗАНЯТОСТИ
}

\author{
(c) 2021 Валеев Эмиль Рамилевич
}

кандидат экономических наук, доцент кафедры управления человеческими ресурсами

Казанский (Приволжский) федеральный университет, Россия, Казань

E-mail: emilv@mail.ru

\section{(c) 2021 Рыжова Ася Сергеевна}

ассистент кафедры управления человеческими ресурсами

Института управления, экономики и финансов

Казанский (Приволжский) федеральный университет, Россия, Казань

E-mail: a.s.ryzhova@yandex.ru

\section{(c) 2021 Шакирьянова Алсу Ильдаровна}

кандидат экономических наук, доцент кафедры управления человеческими ресурсами

Казанский (Приволжский) федеральный университет, Россия, Казань

E-mail: AIShakiryanova@kpfu.ru

В статье рассматривается феномен неформальной занятости и его влияние на отдельных лиц и общество, особенно в контексте глобального экономического спада. Доля неформальной занятости, как правило, увеличивается во время экономических потрясений, поскольку неформальная работа может служить буфером, когда люди увольняются в формальном секторе. Несмотря на то, что неформальная занятость предлагает запасной вариант для поддержания средств к существованию, она сопряжена с определенными издержками. Прежде всего, в периоды кризиса, потрясений, в первую очередь, уязвима неформальная работа.

Ключевые слова: неформальная занятость, рабочие места, кризис, социальное обеспечение, государство, трудовое законодательство, трудовые договора, уровень бедности, мировая рабочая сила, профессиональные риски, заработная плата.

Вопросы занятости и управления человеческим капиталом также рассматривают такой феномен, как неформальная занятость. Общее понятие данного феномена предполагает целенаправленную деятельность, формирование рабочих мест, а также видов деятельности, связанных с производством и коммерциализацией легальных товаров и услуг, которые не зарегистрированы или не защищены государством.

Исходя из определений, данных Государственным комитетом РФ по статистике, можно выделить следующие признаки участников неформальной занятости. Особенности, характеризующие неформальную занятость в отечественной практике, представлены на рисунке 1.

K занятым в неформальном секторе относится население, субъектный состав которого представлен на рисунке 2. Субъектный состав определен, исходя из официальной информации, представленной Государственным комитетом по статистике в РФ.

На начало 2020 года количество неформаль- но занятого населения составило 14 млн. 800 тыс. населения по данным Государственного комитета РФ по статистике. В эти данные включены родственные лица, работающие у индивидуальных предпринимателей.

По данным рейтингового агентства, феномен неформальной занятости типичен таким регионам как Северный Кавказ, Республике Алтай, Крыму, Ставропольскому краю, Бурятии. Меньше всего доля занятых в неформальном секторе в Северо-Западном округе, Дальнем Востоке, Западной Сибири [8].

Лица, занятые в неформальном секторе, не претендуют на получение различных форм системы социальной защиты, в том числе, и социального страхования, медицинского страхования и пенсионного обеспечения. K тому же, статистические данные свидетельствуют, что участники сектора неформальной занятости, осведомлены как о возможном недополучении данных форм защиты, так и об их наличии и возможности в будущем получить в случае на- 
К занятым в неформальном секторе относятся лица, которые в течение обследуемого периода были заняты, по меньшей мере, в одной из производственных единиц неформального сектора независимо от их статуса занятости и от того, являлась ли эта работа для них основной или дополнительной.

В качестве критерия определения единиц неформального сектора принят критерий отсутствия государственной регистрации в качестве юридического лица.

С 2017 г. учитываются только лица, производящие продукцию преимущественно для продажи. До 2017 г. в численности занятых учитывались как лица, производящие продукцию преимущественно для продажи, так и продающие излишки своей продукции

Концепция неформального сектора отличается от понятия скрытой (теневой) экономики

Подавляющее большинство производственных единиц неформального сектора предоставляет товары и услуги, производство и распространение которых совершенно законно.

Деятельность предприятий неформального сектора не обязательно связана с преднамеренным уклонением от уплаты налогов или взносов на социальное страхование, или нарушением трудового законодательства, или других правил

Однако некоторые из предприятий неформального сектора предпочитают оставаться незарегистрированными или нелицензируемыми, чтобы избежать выполнения всех или некоторых правил и таким образом снизить издержки производства

Puc. 1. Особенности, характеризующие неформальную занятость в России [7].

индивидуальные предприниматели

лица, работающие по найму физических лиц

помогающие члены семьи в собственном деле, принадлежащем кому-либо из родственников

занятые в собственном домашнем хозяйстве по производству продукции сельского, лесного хозяйства, охоты и рыболовства для продажи или обмена

работающие на индивидуальной индивидуального предпринимателя

Puc. 2. Структура участников неформальной занятости в России [7]. 
Таблица 1. Численность занятых в неформальном секторе по категориям и статусу [7]

\begin{tabular}{|c|c|c|c|c|c|c|c|}
\hline \multirow{3}{*}{ Субеъкты } & \multirow{3}{*}{$\begin{array}{c}\text { Всего, тыс. } \\
\text { человек }\end{array}$} & \multicolumn{6}{|c|}{ из них } \\
\hline & & \multirow{2}{*}{$\begin{array}{c}\text { работающие } \\
\text { по найму }\end{array}$} & \multirow{2}{*}{$\begin{array}{l}\text { работающие } \\
\text { не по найму }\end{array}$} & \multicolumn{4}{|c|}{ в том числе } \\
\hline & & & & работодатели & $\begin{array}{c}\text { самостоятельно } \\
\text { занятые }\end{array}$ & $\begin{array}{c}\text { члены } \\
\text { производственных } \\
\text { кооперативов }\end{array}$ & $\begin{array}{c}\text { помогающие } \\
\text { на семейном } \\
\text { предприятии1) }\end{array}$ \\
\hline \multicolumn{8}{|l|}{$\begin{array}{c}\text { Занятые - } \\
\text { всего }\end{array}$} \\
\hline 2017 & 14324 & 8936 & 5388 & 876 & 4266 & 0,2 & 246 \\
\hline 2018 & 14581 & 9024 & 5557 & 961 & 4310 & $\ldots$ & 287 \\
\hline 2019 & 14800 & 9395 & 5405 & 915 & 4242 & $\ldots$ & 248 \\
\hline \multicolumn{8}{|l|}{ Мужчины } \\
\hline 2017 & 7991 & 4837 & 3154 & 595 & 2432 & 0,2 & 127 \\
\hline 2018 & 8079 & 4872 & 3207 & 645 & 2426 & $\ldots$ & 137 \\
\hline 2019 & 8181 & 5081 & 3101 & 597 & 2369 & $\ldots$ & 135 \\
\hline \multicolumn{8}{|l|}{ Женщины } \\
\hline 2017 & 6334 & 4099 & 2234 & 281 & 1834 & $\ldots$ & 119 \\
\hline 2018 & 6503 & 4153 & 2350 & 316 & 1884 & $\ldots$ & 150 \\
\hline 2019 & 6619 & 4315 & 2304 & 319 & 1873 & $\ldots$ & 113 \\
\hline
\end{tabular}

ступления страховых случаев, например, или же, в случае декретного отпуска, а также получения инвалидности. Как считают социологи, данных лиц, работающих в неформальном статусе, возможно привлекает так называемая «экономия» от того, что они полностью или частично неформальны и не учтены в государственных структурах, таким образом, никаких взносов на социальное обеспечение, никаких налоговых платежей, никаких обязательных трудовых норм. Положительным фактором также является наличие свобод для инновационных предпринимательских действий. Широкое распространение различных форм неофициальной занятости в развивающихся странах поражает воображение. К примеру, в ряде развивающихся стран до 65\% несельскохозяйственных рабочих мест можно было бы считать неофициальным [1].

Во времена кризиса неформальные работники подвергаются вероятному снижению заработной платы из-за притока уволенных работников из формального сектора и возвращающихся мигрантов. Они также первыми теряют свои рабочие места. Во-вторых, потенциальный рост неформальной занятости ставит работников в статус социально-незащищенной части населения. Отсутствие формальной социальной защиты перед лицом рисков для здоровья и профессиональных рисков, а также отсут- ствие защиты трудовых прав подвергает многих неформальных работников более высокому риску бедности, чем в противном случае, и может существенно повысить уровень бедности.

Зарубежные ученые, подчеркивают, что «феномен» неформальной занятости представляет собой вполне нормальное явление, и даже является фактором, способствующим развитию экономики и ускорению темпов экономического развития. В зарубежных странах, количество сотрудников в сфере несельскохозяйственного сектора, представляющего сектор неформальной занятости, достигает порядка свыше 900 млн. человек. При учете количества нанятых в сфере сельского хозяйства в развивающихся странах, их уровень численности составляет более 2 млрд. населения. Как свидетельствует объективная статистика, в настоящее время, сфера неформальной занятости представляет значительный количественный показатель в размере до двух третей мировой рабочей силы. Особенно это характерно для стран Африки к югу от Сахары и Южную. В Азии более $80 \%$ несельскохозяйственных рабочих мест являются неформальными местами работы. Вдобавок ко всему этому, большинство сельскохозяйственных рабочих мест также являются неформальными, в том числе у самозанятых фермеров, а также подавляющего большинства поденщиков и случайных работников [9]. 
Когда в 1970-х годах впервые была признана неформальная занятость, дискуссии по этому вопросу были сосредоточены на небольшой группе стран с низким уровнем дохода. Неэффективные государственные институты, громоздкие процессы регистрации и общее недоверие к правительству - все факторы, которые стимулируют создание рынка за пределами официальных структур страны, - рассматривались как верные признаки отсталости. Часто предполагается, что эти факторы, а, следовательно, и неформальная занятость, исчезнет в ходе экономического развития.

Реальность не оправдывает такого оптимизма. Неформальная работа становится все более нормой, не в последнюю очередь в странах со средним уровнем дохода, и она является значительной, даже в некоторых странах с высоким уровнем дохода. В некоторых случаях доля рабочих мест, выполняемых за пределами официальных структур страны, может составлять более половины всех несельскохозяйственных рабочих мест и до 90 процентов, если включить сельскохозяйственные рабочие места.

Распространенность неформальной занятости увеличилась, несмотря на экономический рост. К примеру, в странах Юго-Восточной Азии и Латинской Америки, в среднем, экономический рост за последние 20 лет сопровождался увеличением, а не снижением показателей неформальной занятости [9].

Большинство неформальных работников в развивающихся странах являются самозанятыми и работают самостоятельно или владеют очень небольшими предприятиями и управляют ими. Неформальность часто является средством снижения затрат на рабочую силу. Как ответ на усиление международной конкуренция и недоступная деловая среда могут привести к тому, что некоторые законодательные меры защиты работников формального сектора, в том числе в некоторых странах ОЭСР, могут быть сведены на нет, что, по сути, приведет к созданию неформальной рабочей силы. Например, в том, что стало известно, как ложная самозанятость, люди каждый день заключают субподряд с одним и тем же работодателем - добровольно или нет - и, таким образом, работают в качестве самозанятых подрядчиков, чтобы обойти юридические требования нормальных рабочих отношений.

Существуют различные виды неформальной занятости, что затрудняет для оценки этого сложного явления. Уровни неформальной занятости сильно различаются в разных странах, достигая самых высоких показателей в странах Африки к югу от Сахары, где около 80\% всех занятых работают неофициально, за которыми следуют Юго-Восточная Азия и Латинская Америка.

Неформальная занятость может быть результатом как того, что люди отстраняются от формальной работы, так и того, что люди добровольно отказываются от формальных структур.

Например, во многих странах со средним уровнем дохода структуры стимулирования вытесняют частных лиц и предприятия из формального сектора. В Латинской Америке от формальных работников часто требуют платить за обязательный набор льгот, некоторые из которых они даже не хотят. Аналогичным образом, многие предприятия отказываются от формальной структуры, поскольку неэффективность регистрации бизнеса и администрирования социального обеспечения увеличивает затраты на пребывание в формальной экономике.

Экономическое развитие также играет важную роль в определении распространенности неформальной занятости. Периоды быстрого экономического роста часто совпадают с резким увеличением неформальной занятости. Однако устойчивое экономическое развитие может способствовать снижению уровня неформальной занятости.

Например, долгосрочный рост дохода на душу населения явно связан с более низким уровнем неформальной занятости.

В течение многих лет анализ политики в области неформальной занятости в основном был сосредоточен на менее развитых странах. Неформальные работники часто сосредоточены в сельском хозяйстве, домашнем хозяйстве или ручной работе; они могут включать лиц, которые являются самозанятыми в том смысле, что они не работают на какого-либо конкретного работодателя или фирму. Независимо от того, являются ли они самозанятыми или работают на других лиц, физические лица (и их работодатели), которые не сообщают о доходах или доходах для целей налогообложения, являются частью неформальной экономики.

По мере взросления и развития капиталистических экономик, установления политики регулирования и защиты трудящихся и расширения социальной помощи неформальный труд 
должен сокращаться. Тем не менее, сегодня неформальный труд остается основной частью экономики как развитых, так и развивающихся стран. Некоторые аналитики предполагают, что доля неформальной работы может увеличиваться отчасти в ответ на расширение глобализации. Новые предприятия расширяются в городских районах, но затраты на открытие предприятий высоки, что заставляет некоторых предпринимателей работать в неформальном секторе и платить более низкую заработную плату, чтобы минимизировать расходы.

Таким образом, актуальны вопросы рассмотрения особенностей формирования неформальной занятости.

Буквальное определение неформального сектора является простым: экономическая деятельность, которая находится вне налоговой и регулятивной политики. Это определение применимо как к работникам, так и к отдельным лицам или компаниям, на которые они работают. В отличие от этого, формальная или стандартная занятость обычно относится к регулярным соглашениям о заработной плате и работе в месте нахождения работодателя или под наблюдением, или политикой работодателя, где заработная плата и доход сообщаются правительству в соответствии с требованиями закона [4, с. 140].

В мировой практике нет четкого консенсуса относительно того, что представляет собой неформальная занятость. На самом базовом уровне неформальная занятость означает занятость, которая происходит вне налоговых и регулирующих систем.

K составляющим неформальной занятости отнесена также безвозмездная работа, выполняемая на предприятии, приносящем доход», включая людей, работающих по договорам субподряда, заключенным или заключенным агентами по найму [5, с. 45].

То есть термин неформальная занятость обычно включает в себя все виды экономической деятельности, которые действуют вне государственных правил, налогов, правил и контроля. Американский социолог Алехандро Портес (Университет Джона Гопкинса), например, определяет неформальную занятость как работу, выполняемую в приносящих доход видах деятельности, которые функционируют без формальных соглашений о заработной плате.

В развитых странах, различие между формальной и неформальной экономической де- ятельностью не всегда является четким. Например, неформальная занятость сходна в некоторых отношениях (например, работа без постоянной привязки к конкретной фирме, не покрываемая льготами, предоставляемыми работодателями) с нестандартной или условной занятостью (например, временная, прерывистая, неполный рабочий день, дневной труд и контрактные работники), которая может работать в формальном секторе. Кроме того, люди часто смешивают формальную, неформальную и нестандартную работу, например, работая на второй работе или подрабатывая, иногда «неофициально»[2, с. 325].

Неформальная занятость, как правило, игнорируется в политических кругах. Ее часто рассматривают с точки зрения черного рынка (т.е. преступной и незаконной) деятельности, нелегальных иммигрантов или уклонения от уплаты налогов белыми воротничками. Однако, помимо этих стереотипов, неформальная занятость представляет собой различные экономические механизмы. Существование неформального рынка имеет последствия для многих вариантов политики, касающихся работников и их семей, а также предприятий (особенно предпринимательской деятельности и малого бизнеса) [1, с. 21.].

Государственная политика всячески поощряет формальную занятость. Работники получают выгоду от участия в формальном секторе. Многие развитые страны исходят из того, что неформальная занятость не должна поощряться; а также исходят из того, что формальная занятость лежит в основе развития человеческого капитала и является ключом к достижению целей политики социального обеспечения, связанных с повышением индивидуальной экономической самодостаточности.

Рассмотрение данных позволяет сделать вывод о том, что факторы и предпосылки возникновения неформальной занятости в разных странах различны. Но выделяют основные группы причин, способствующие его возникновению. В общем смысле выделяют экономические, социальные, правовые, политические, антропологические и социокультурные причины возникновения неформальной занятости. На рисунке 3 представлены основные экономические причины возникновения неформальной занятости. На рисунке 4 представлены основные социальные причины неформаальной занятности.

Описанные экономические причины явля- 
ются первостепенными в области увеличения масштабов неформальной занятости. Многие компании и физические лица именно из-за налоговых сборов избегают регистрации занятости, либо неофициального найма персонала. Налоговая нагрузка на предприятия в России существенная, тем более если компания испытывает нехватку собственных средств и имеет большие дебиторские задолженности. Далее рассмотрим основные социальные причины возникновения неформальной занятости.

Невысокие заработные платы, низкий уровень жизни населения, высокий процент безработных, а также неравномерное распределение ВВП подталкивает граждан соглашаться на неофициальную работу. Многие неофициально занятые лица не имеют оконченного сред- не-специального либо высшего образования, в связи с чем вынуждены соглашаться на любые условия труда, предлагаемые компаниями.

Таким образом, к основным причинам возникновения неформальной экономики можно отнести стремление уклонится от налогов, в связи с низким уровнем жизни. Негативными последствиями неформальной занятости считаются введение высоких налоговых ставок и снижение платежеспособности населения, неспособность эффективно ориентировать социальную защиту и управлять ею, развитие недобросовестной конкуренции и стимулы к непродуктивной деятельности, неэффективность производства в неформальной экономике, содействие нелегальной иммиграции.

Но неформальная занятость - это не просто

1) высокий процент налогообложения (налоги на прибыль, подоходный налог и т.п.);

2) влияние негативных последствий кризиса финансовой системы (угроза роста инфляции, сокращение объемов кредитования, сворачивание инвестиционных программ);

3) реструктуризация сфер хозяйственной деятельности;

4) деятельность незарегистрированных экономических структур.

Puc. 3. Экономические причины возникновения неформальной занятости [3, с. 101].

1) низкий уровень жизни населения, который провоцирует развитие скрытых видов экономической деятельности;

2) высокий уровень безработицы, вынуждающий часть трудоспособного населения, не имеющего официального дохода, на получение дохода любым способом;

3) неравномерное распределение валового внутреннего продукта.

Рuc. 4. Основные социальные причины неформальной занятости [5, с. 44-47]. 
аспект отсталости, сдерживающий экономический рост. В некоторых странах использование неофициальных каналов действительно может оказать положительное влияние на экономическое развитие.

Например, если громоздкие процедуры регистрации и другая административная волокита препятствуют созданию официальных предприятий, неформальные условия труда могут способствовать поощрению предпринимательского поведения. Хорошим примером этого является Южная Африка, где, избегая формальных структур, таких как концессии на маршруты, лицензионные требования и правила техники безопасности, предприниматели создали многомиллионный бизнес на мини-автобусах.

В других случаях использование неформальных структур может быть обусловлено не столько добровольным решением, сколько необходимостью. Для многих людей неформальная занятость является важной стратегией получения средств к существованию и играет решающую роль в сокращении масштабов нищеты и социальных трудностей. Однако неформальная работа оставляет людей без надлежащей социальной защиты и приводит к тому, что они оказываются на непроизводительной и ненадежной работе. В этих случаях отсутствие формальных структур является причиной, а не решением проблемы отставания экономического развития.

Многие люди зарабатывают на жизнь неформальной занятостью, но неформальная работа имеет серьезные последствия как для отдельных людей, так и для общества. Помимо уровня заработка, неформальная занятость делает основные права уязвимыми и трудными для защиты. Как таковой, он может быть основной причиной бедности и в других отношениях, помимо доходов. Большинство тех, кто работает неофициально, недостаточно защищены от различных рисков, которым они подвергаются: болезней или проблем со здоровьем, небезопасных усло- вий труда и возможной потери заработка. Это особенно важно для бедных, чей труд, безусловно, является их самым значительным достоянием.

Для общества в целом повсеместная неформальная занятость подрывает способность государства обеспечивать работникам справедливые условия труда, включая надлежащее рабочее время и правила техники безопасности, а также адекватную оплату труда. Стабильно высокий уровень неформальной занятости снижает налоговые поступления и способность развивать системы социального обеспечения, основанные на налогах и взносах. Они также подразумевают неадекватное использование имеющихся: считается, что человеческие ресурсы как неформальные рабочие места связаны с потерей эффективности и производительности.

Кроме того, размер и структура неформальной занятости влияют на структуру экономического роста. Неясно, является ли неформальная занятость тормозом производительности или может, по крайней мере временно, быть двигателем роста. Например, многие наблюдатели утверждают, что высокая степень неформальной занятости может снизить конкурентоспособность экономики, поскольку неформальные фирмы предпочитают оставаться небольшими и имеют меньший доступ к ресурсам, не могут вступать в формальные деловые отношения - все это факторы, снижающие их производительность. Другие подчеркивают, что в странах с формирующейся экономикой, таких как в Китае неформальная занятость обеспечивает необходимую гибкость для создания инновационных предпринимателей, которые стимулируют экономический рост. Какова бы ни была обоснованность этих двух противоположных взглядов, небольшие фирмы, характеризующиеся низкой производительностью, по сравнению с инновационными предпринимателями с высоким уровнем гибкости широко распространены.

\section{Библиографический список}

1. Абдуллоев Х.А. Историко-генетический анализ формирования теории неформальной занятости // В сборнике: Национальные экономические системы в контексте формирования глобального экономического пространства. Сборник научных трудов IV Международной научно-практической конференции. 2018. С. 20-22.

2. укетлова Л.Х. Социальные последствия неформальной занятости и проблемы социальной ответственности // В сборнике: Актуальные проблемы истории, теории и методологии социальной работы. Материалы конференции. 2019. С. 325. 
3. Залалтдинов М.М., Гильмутдинова А.Ш., Аскарова Р.Р. Теневая экономика: сущность, причины существования и последствия // В сборнике: Развитие бухгалтерского учета и аудита в условиях цифровой экономики Сборник научных трудов по материалам Международной научно-практической конференции. 2019. С. 101.

4. Тумунбаярова Ж.Б., Анциферова М.Д. Неформальная занятость: причины и факторы, определяющие ее уровень // Теневая экономика. 2018. Т. 2. № 4. С. 140.

5. Халимова С.И., Иикильдина Г.Р. Некоторые вопросы неформальной занятости населения // В сборнике: Человек. Общество. Культура. Социализация. материалы XV Международной молодежной научно-практической конференции. 2019. С. 45.

6. Циклаури В.Ю., Белоусова Л.С., Девятилова А.И. Теневая экономика в мировом экономическом пространстве // Известия Юго-Западного государственного университета. Серия: Экономика. Социология. Менеджмент. 2017. Т. 7, № 3 (24). С. 15.

7. Федеральная служба государственной статистики. Электронный ресурс: [Режим доступа] https:/ rosstat.gov.ru/folder/11191? print=1 (дата обращения: 28.12.2021).

8. Росстат сообщил о росте неформальной занятости в России. Электронный ресурс: [Режим доступа] https:/ www.rbc.ru/economics/05/09/2019/5d6e74fb9a794709eeba4f8chttps://www.rbc.ru/economics/05/09/2019/5d6 e74fb9a794709eeba4f8c (дата обращения: 28.12.2021).

9. The Shadow Economy and Shadow Economy Labor Force: What Do We (Not) Know? Электронный ресурс: [Режим доступа] https://www.econstor.eu/bitstream/10419/51986/1/669470910. pdf (дата обращения: 28.12.2021). 